\title{
Investment Timing with Incentive-Disincentive Contracts under Asymmetric Information*
}

\author{
Takashi Shibata ${ }^{1}$, Michi Nishihara ${ }^{2}$ \\ ${ }^{1}$ Graduate School of Social Sciences, Tokyo Metropolitan University, Tokyo, Japan \\ ${ }^{2}$ Graduate School of Economics, Osaka University, Osaka, Japan \\ Email: tshibata@tmu.ac.jp, nishihara@econ.osaka-u.ac.jp
}

Received January 15, 2012; revised February 13, 2012; accepted February 21, 2012

\begin{abstract}
This paper examines a manager's investment timing in the presence of asymmetric information between an owner and the manager. In particular, we extend the asymmetric information problem by incorporating not only an incentive but also disincentive. Investment timing is delayed more under asymmetric information than under symmetric information. However, investment timing under asymmetric information converges to the symmetric information investment timing by making the disincentive (penalty) for the manager's untruthful report sufficiently large. Consequently, by adopting an enlarged set of incentive-disincentive contracts framework, we showed that there is a relationship between the symmetric and asymmetric information problems.
\end{abstract}

Keywords: Real Options; Asymmetric Information; Incentive-Disincentive; Principal-Agent Problem

\section{Introduction}

In most modern corporations, owners delegate the corporate management to managers, taking advantage of managers' special skills and expertise. In this situation, asymmetric information is likely to exist between them. Asymmetric information is a situation where a portion of the underlying state variable is privately observed by the managers, while it is unobservable by the owners. Managers with private information have an incentive to provide a false report and then divert free cash flow to themselves. Thus, asymmetric information leads to agency conflicts.

The real options model has become a standard framework for investment timing decisions in corporate finance. For the interested reader, Dixit and Pindyck [1] provide an excellent overview of the standard real options approach. The main result is to obtain the optimal investment timing and project value under uncertainty. In the standard real options model, however, there are no agency conflicts between owners and managers, because

\footnotetext{
${ }^{*}$ This research was partially supported by a Grant-in-Aid by the Excellent Young Researcher Overseas Visit Program (21-2171), the Japan Economic Research Foundation, KAKENHI (22710142, 22710146), the Telecommunications Advancement Foundation, the Zengin Foundation for Studies and Economics and Finance.

${ }^{1}$ Recently, the standard real options model has been extended in various ways. For example, Weeds [3] and Nishihara and Fukushima [4] consider investment timing by taking into account strategic interactions. Bernardo and Chowdhry [5] and Shibata [6] analyse investment decisions under incomplete information.
}

the firm is assumed to be managed by owners. ${ }^{1}$

Several studies have begun the task of incorporating agency conflicts into the real options model. Grenadier and Wang [2] (hereafter GW) develop models of investment timing in the presence of agency conflicts arising from asymmetric information between owners and managers. ${ }^{2}$ In such a situation, owners must design a contract to provide mechanisms for managers to reveal private information truthfully. They assume that the owners give the managers an incentive to reveal the managers' private information. The implied investment timing is then delayed, compared with that under symmetric information, which leads to a decrease in the stock price (owners' value). Although these strategies turn out to be suboptimal, they reduce the owners' losses arising from asymmetric information. Without any mechanism that induces managers to reveal private information truthfully, owners suffer further distortions.

To the best of our knowledge, there has been little examination of such contracts other than the incentive mechanism in a real options model under asymmetric information. Owners may increase their own value by designing other mechanisms to induce managers to reveal private information truthfully. One important way is to use a disincentive mechanism. For example, because

\footnotetext{
${ }^{2}$ While these papers focus on the agency conflicts between owners and managers, a similar problem exists between stockholders and bondholders. Mello and Parsons [7] and Leland [8] examine the agency problem between stockholders and bondholders using the real options approach.
} 
an owner audits a manager at a cost, the owner imposes penalties on the manager if an untruthful report by the manager is detected. ${ }^{3}$ Thus, it is natural to design an optimal contract containing both incentive and disincentive mechanisms. In most modern corporations, the disincentive system is designed so that owners can inspect managers' behaviour.

Shibata [12] (hereafter, S) extends the model of investment timing developed by GW to design a contract with an incentive-disincentive mechanism, in which the owners induce the managers to reveal private information by giving bonuses and imposing penalties when an untruthful report is detected by randomized auditing. Obviously, the incentive-disincentive scheme in the $\mathrm{S}$ model expands on that of the incentive-only scheme in the GW model. Thus, the investment timing distortions in the $\mathrm{S}$ model are smaller than those in the GW model. Nevertheless, penalties are decided by the owners endogenously, and they are restricted to be less than the maximum amount of the managers' diverted cash flows for untruthful reporting. These two features of the model are unreasonable in practice as follows. First, the penalties are specified not by the owners, but by legislation. Second, the penalties are not always restricted to be less than the maximum amount of the managers' diverted cash flows. Suppose that, for example, although the managers divert free cash flows of 30,000 USD to themselves using their information advantage, the managers' untruthful actions are detected during auditing. Then, in the $\mathrm{S}$ model, the managers are fined a penalty of 30,000 USD, which equals the diverted cash flow. However, in practice, a court applying the legislation can impose a penalty (e.g., 50,000 USD) of more than the diverted cash flow of 30,000 USD. Thus, it is reasonable that penalties are imposed on owners exogenously and that the penalties are not always less than the diverted free cash flows when untruthful reporting is detected during auditing.

This paper extends the model of investment timing with incentive-disincentive contracts under asymmetric information between owners and managers by eliminating the assumption that the penalties are less than the diverted cash flows. By assuming that penalties are imposed on the owners exogenously, the penalties may be smaller or larger than the diverted cash flows. Then, the set of incentive-disincentive contracts could be enlarged, compared with those in the S model. This paper highlights how the enlarged set of incentive-disincentive contracts influence investment timing, the stock price (owners' value), and social welfare. In the existing papers discussed above, there is a divergence in investment timing and these values between the symmetric and asymmetric information cases. By adopting an enlarged set of

${ }^{3}$ See Townsend [9], Baron and Besanko [10], and Laffont and Tirole [11]. incentive-disincentive contracts framework, our paper makes the first attempt to bridge the gap between the symmetric and asymmetric information cases.

In our results, the implied investment triggers (timings) can be derived in three feasible regions, depending on the magnitude of the exogenous penalties. The three feasible regions are the incentive-only (bonus-incentive only) region, the incentive-disincentive combination (bonus-incentive and audit-penalty) region, and the disincentiveonly (audit-penalty only) region. The investment trigger in the incentive-only region is equivalent to the one in the GW model. The investment trigger in the combination region includes the one in the $\mathrm{S}$ model. Most importantly, the symmetric information investment trigger of McDonald and Siegel [13] (hereafter MS) can be approximated by making the penalty for the manager's false report sufficiently large. Consequently, by adopting an enlarged set of incentive-disincentive contracts framework, we show that there is a relationship between the symmetric and asymmetric information problems.

We analyse inefficiencies in investment timing, stock price (owners' values), and total social welfare (loss) arising from asymmetric information. An increase in the penalty for managers' cheating makes the suboptimal investment timing under asymmetric information approach the same as the optimal timing under symmetric information, which increases the stock price (i.e., increases the efficiency of the owners' welfare). In contrast, an increase in the penalty does not necessarily rise the total social welfare. Thus, we conclude that an owner's rationality does not necessarily increase total social rationality. In other words, an increase in the penalty does not necessarily increase the efficiency of the total social welfare while it always increases the efficiency of the owners' welfare.

The paper proceeds as follows. Section 2 describes the framework of our model. It is useful to consider the symmetric information problem as a benchmark before analysing the asymmetric information problem. Section 3 provides the solution to the asymmetric information problem. We then discuss the properties of the solution. Section 4 investigates the numerical implications. Section 5 concludes. Technical developments are contained in two appendices. Appendix A contains proofs of the results in the paper. Appendix B contains the solutions to the optimization problems of $\mathrm{GW}$ and $\mathrm{S}$ to compare our results with theirs.

\section{Model}

In this section, we formulate our model. Subsection 2.1 describes the model framework. Subsection 2.2 formulates the asymmetric information problem. Subsection 2.3 , as a benchmark, provides the solution to the symme- 
tric information problem.

\subsection{Setup}

The owner of a firm has the option to invest in a single project. We assume that the owner (principal) delegates the investment decision to a manager (agent). Throughout our analysis, we assume that the owner and the manager are risk neutral and aim to maximize their expected pay-offs.

If the investment option is exercised at time $t$, the firm pays the one-time fixed cost $I>0$ and receives cash flow $X_{t}$, which follows a geometric Brownian motion:

$$
\mathrm{d} X_{t}=\mu X_{t} \mathrm{~d} t+\sigma X_{t} \mathrm{~d} z_{t}, \quad X_{0}=x
$$

where $z_{t}$ denotes a standard Brownian motion, and where $\mu>0$ and $\sigma>0$ are positive constants. For convergence, we assume that $r>\mu$ where $r>0$ is a constant interest rate. ${ }^{4} \mathrm{We}$ assume that the one-time fixed cost, $I$, takes one of two possible values: $I_{1}$ or $I_{2}$ with $I_{2}>I_{1}$, where $I_{i}>0$ for all $i \in\{1,2\}$. We denote $\Delta I:=I_{2}-I_{1}>0$. We assume that $I_{1}$ represents "lower cost" expenditure and $I_{2}$ "higher cost" expenditure. The probability of drawing $I_{1}$ equals $q$, an exogenous variable.

Let $V\left(x ; I_{i}\right)$ denote the project value for $I=I_{i}$ $(i \in\{1,2\})$. The value is defined as

$$
V\left(x ; I_{i}\right)=\sup _{\tau_{i} \geq 0} \mathbb{E}^{x}\left[e^{-r \tau_{i}}\left(X_{\tau_{i}}-I_{i}\right)\right], \quad i \in\{1,2\},
$$

where $\mathbb{E}^{x}[\cdot]$ denotes the expectation operator given that $X_{0}=x$, and $\tau_{i}$ is the stopping time at which the investment is exercised once $X_{t}$ arrives at the threshold $x_{i}=x\left(I_{i}\right)$ for $I=I_{i}$, i.e., $\tau_{i}:=\inf \left\{t \geq 0 ; X_{t}=x_{i}\right\}$

Using standard arguments, the project value is rewritten as

$$
V\left(x ; I_{i}\right)=\max _{x_{i}}\left(\frac{x}{x_{i}}\right)^{\beta}\left(x_{i}-I_{i}\right), \quad i \in\{1,2\}
$$

where $\beta=1 / 2-\mu / \sigma^{2}+\sqrt{\left(\mu / \sigma^{2}-1 / 2\right)^{2}+2 r / \sigma^{2}}>1$. In this paper, the current state value $X_{0}=x$ is sufficiently low that the investment is not undertaken immediately.

The cash flow, $X_{t}$, is assumed to be observed by both the owner and the manager. However, the one-time cost, $I$, is observed privately only by the manager. ${ }^{5}$ Immediately after making a contract with the owner at time zero, the manager observes whether the cost expenditure is of

\footnotetext{
${ }^{4}$ The assumption $r>\mu$ is needed to ensure that the value of the firm is finite.

${ }^{5}$ The assumption that a portion of the project value is observed privately only by one person (here, the manager) and not observed by the other (here, the owner) is quite common in the asymmetric information litrature. An excellent overview of the analysis of asymmetric information situations is found in Fudenberg and Tirole [14] and Laffont and Martimort [15].
}

"lower cost" or "higher cost." On the other hand, the owner cannot observe the true value of $I$. Therefore, the owner must induce the manager to reveal private information truthfully at the time when the manager undertakes the investment. Otherwise, the owner suffers from further losses. Suppose, for example, the manager observes $I=I_{1}$ as the realized value of $I$. Then the manager diverts the difference $\Delta I>0$ to himself/herself by reporting $I=I_{2}$ to the owner. To prevent the diversion, the owner must encourage the manager to report the true value by providing incentives.

\subsection{Asymmetric Information Problem}

In this subsection, we formulate the owner's maximization problem under asymmetric information. As explained earlier, under asymmetric information, the owner must induce the manager to reveal the manager's private information truthfully.

In this paper, the owner designs a contract at time zero that commits the owner to give the incentive-disincentive to the manager at the time of investment. Renegotiation is not allowed. While commitment may cause ex post inefficiency in investment timing, it increases the ex ante owner's option value. To reveal private information, we assume that the owner provides a bonus-incentive $w_{i}$ and/or audits the manager with a probability $p_{i}$ at the time of investment.

The audit technology allows the owner at the cost to verify the state announced by the manager, and to impose a penalty on the manager for cheating when a false report is detected. We assume that a penalty $P \geq 0$ is an exogenous constant, and that the cost of auditing $c\left(p_{i}\right)$ is a function of probability $p_{i}$ with $c(0)=0, c^{\prime}\left(p_{i}\right)>0$, $c^{\prime \prime}\left(p_{i}\right)>0$, and $\lim _{p_{i} \uparrow 1} c\left(p_{i}\right)=+\infty$. These assumptions are intuitively reasonable. The first assumption is that there is no cost incurred if the owner does not use the audit technology. The second and third assumptions imply that $c\left(p_{i}\right)$ is strictly increasing and convex in $p_{i}$. The final assumption is that complete auditing incurs a huge cost that the owner cannot pay.

Thus, the contract in the asymmetric information problem is modelled as a mechanism: ${ }^{6}$

$$
M^{\mathrm{A}}=\left(x_{i}, w_{i}, p_{i}\right), i \in\{1,2\} \text {. }
$$

Let superscript " $A$ " refer to the asymmetric information (agency) problem. ${ }^{7}$

Then, the asymmetric information problem is to maximize the owner's option value through choice of the me-

\footnotetext{
${ }^{6} \mathrm{We}$ need not examine the possibility of a pooling equilibrium. This is because a pooling equilibrium is always dominated by a separating equilibrium.

${ }^{7}$ Because at the equilibrium the manager reveals truthfully the true $I_{i} \underset{\sim}{\text { as }}$ private information, we make no distinction between the reported $\tilde{I}_{i}$ and the true $I_{i}$.
} 
chanism $M^{\mathrm{A}}$, i.e.,

$$
\begin{aligned}
& \max _{x_{1}, x_{2}, w_{1}, w_{2}, p_{1}, p_{2}} q\left(\frac{x}{x_{1}}\right)^{\beta}\left(x_{1}-I_{1}-w_{1}-c\left(p_{1}\right)\right) \\
& +(1-q)\left(\frac{x}{x_{2}}\right)^{\beta}\left(x_{2}-I_{2}-w_{2}-c\left(p_{2}\right)\right),
\end{aligned}
$$

subject to

$$
\begin{gathered}
\left(\frac{x}{x_{1}}\right)^{\beta} w_{1} \geq\left(\frac{x}{x_{2}}\right)^{\beta}\left(w_{2}+\Delta I-p_{2} P\right), \\
\left(\frac{x}{x_{2}}\right)^{\beta} w_{2} \geq\left(\frac{x}{x_{1}}\right)^{\beta}\left(w_{1}-\Delta I-p_{1} P\right), \\
q\left(\frac{x}{x_{1}}\right)^{\beta} w_{1}+(1-q)\left(\frac{x}{x_{2}}\right)^{\beta} w_{2} \geq 0, \\
w_{i} \geq 0, \quad i \in\{1,2\}, \\
1 \geq p_{i} \geq 0, \quad i \in\{1,2\} .
\end{gathered}
$$

Here, the objective function (4) is the ex ante owner's option value.

Constraints (5) and (6) are the ex post incentive-compatibility constraints for the manager under states $I_{1}$ and $I_{2}$, respectively. Consider, for example, constraint (5). The manager's payoff in state $I_{1}$ is $\left(x / x_{1}\right)^{\beta} w_{1}$ if he/she tells the truth, but it is $\left(x / x_{2}\right)^{\beta}\left(w_{2}+\Delta I-p_{2} P\right)$ if he/she instead claims that it is state $I_{2}$. Thus, he/she tells the truth if (5) is satisfied. Constraint (6) follows similarly. Constraint (6) will be shown not to be binding. Thus, only constraint (5) is relevant to our discussion.

Constraints (7) and (8) are the ex ante participation constraint and the ex post limited-liability constraints, respectively. Constraints (8) ensure that the manager makes an agreement about employment. For example, if $w_{2}<0$, then the manager would refuse the contract on learning that $I=I_{2}$. In addition, it is straightforward to show that constraint (8) implies constraint (7). Thus, only constraint $w_{1} \geq 0$ will be relevant to our discussion.

Constraint (9) is obvious, where $p_{i}$ is the probability of an audit.

Before analysing the asymmetric information problem, we first review briefly the symmetric information problem.

\subsection{Symmetric Information Problem (Standard Real Options Model)}

In this subsection, we consider the optimization problem when the owner observes the true value of $I$. This problem is equivalent to the problem in which there is no delegation of the investment decision because the manager has no informational advantage. Then we have $w_{i}=0$ and $p_{i}=0$ for all $i \quad(i \in\{1,2\})$. Thus, the contract $M^{*}$ in the symmetric information problem is modelled as

$$
M^{*}=\left(x_{i}\right), \quad i \in\{1,2\} .
$$

Let superscript "asterisk" refer to the symmetric information (no-agency) problem.

In the symmetric information case, the owner's maximization problem is defined as

$$
\max _{x_{1}, x_{2}} q\left(\frac{x}{x_{1}}\right)^{\beta}\left(x_{1}-I_{1}\right)+(1-q)\left(\frac{x}{x_{2}}\right)^{\beta}\left(x_{2}-I_{2}\right)
$$

where $x<x_{i} \quad(i \in\{1,2\})$. The solutions are

$$
x_{i}^{*}=\theta I_{i}=\frac{\beta}{\beta-1} I_{i} .
$$

By substituting these solutions, we have

$$
\pi^{*}(x):=q\left(\frac{x}{x_{1}^{*}}\right)^{\beta}\left(x_{1}^{*}-I_{1}\right)+(1-q)\left(\frac{x}{x_{2}^{*}}\right)^{\beta}\left(x_{2}^{*}-I_{2}\right)
$$

We employ these results as a benchmark which is the same as those in the standard (MS) model.

\section{Solution}

In this section, we provide the solution to the asymmetric information problem that was described in the previous section. We then discuss some properties of the solution.

\subsection{A Simplified Asymmetric Information Problem}

Although the optimization problem is subject to seven inequality constraints, we can simplify the problem in the following three steps. In this subsection, we simplify the asymmetric information problem.

First, (7) is automatically satisfied, because (8) implies (7). Second, a manager in state $I_{2}$ does not have the incentive to tell a lie as a manager in state $I_{1}$, because the manager in state $I_{2}$ suffers a loss from such a false announcement. Thus, (6) is satisfied automatically, and $p_{1}^{\mathrm{A}}=0$ and $w_{2}^{\mathrm{A}}=0$ are obtained at the optimum. Finally, $p_{2} \leq 1$ in (9) is satisfied automatically. This statement is shown by $\lim _{p_{2} \uparrow 1} c\left(p_{2}\right)=+\infty$ and $c^{\prime}\left(p_{2}\right)>0$ for any $p_{2}$.

As a result, the simplified optimization problem is given as

$$
\begin{gathered}
\max _{x_{1}, x_{2}, w_{1}, p_{2}} q\left(\frac{x}{x_{1}}\right)^{\beta}\left(x_{1}-I_{1}-w_{1}\right) \\
+(1-q)\left(\frac{x}{x_{2}}\right)^{\beta}\left(x_{2}-I_{2}-c\left(p_{2}\right)\right),
\end{gathered}
$$

subject to 


$$
\left(\frac{x}{x_{1}}\right)^{\beta} w_{1} \geq\left(\frac{x}{x_{2}}\right)^{\beta}\left(\Delta I-p_{2} P\right), w_{1} \geq 0, \quad p_{2} \geq 0,
$$

where $x<x_{i}$ for all $i \quad(i \in\{1,2\})$.

\subsection{Optimal Contracts}

We first define the three feasible regions that serve to determine the characteristics of the solution. The nature of the solution depends on the magnitude of the penalty $P$. The contract can be derived in three possible regions: the incentive-only (bonus-incentive only, $\mathrm{Ab}$ ) region, the incentive-disincentive (combination, Ac) region, and the disincentive-only (audit-penalty only, Aa) region. Let superscripts "Ab", "Ac", and "Aa" refer to the optimums for the three feasible regions, respectively.

As shown in Appendix A, we can obtain the following results.

Proposition 1 Suppose that the penalty is finite. In the asymmetric information problem, the optimal contract $M^{\mathrm{A}}=\left(x_{1}^{\mathrm{A}}, w_{1}^{\mathrm{A}}, p_{1}^{\mathrm{A}}, x_{2}^{\mathrm{A}}, w_{2}^{\mathrm{A}}, p_{2}^{\mathrm{A}}\right)$ is as follows:

Incentive-only (bonus-only, $\mathrm{Ab}$ ) region: $0 \leq P<((1-q) / q) c^{\prime}(0)$

$$
\begin{gathered}
\left(x_{1}^{\mathrm{Ab}}, w_{1}^{\mathrm{Ab}}, p_{1}^{\mathrm{Ab}}\right)=\left(x_{1}^{*}, w_{1}^{\mathrm{GW}}, 0\right), \\
\left(x_{2}^{\mathrm{Ab}}, w_{2}^{\mathrm{Ab}}, p_{2}^{\mathrm{Ab}}\right)=\left(x_{2}^{\mathrm{GW}}, 0,0\right),
\end{gathered}
$$

where $x_{2}^{\mathrm{GW}}$ and $w_{1}^{\mathrm{GW}}$ are the investment trigger for $I=I_{2}$ and the bonus for $I=I_{1}$ in GW model as shown in Appendix $B$.

Incentive-disincentive (combination, Ac) region: $((1-q) / q) c^{\prime}(0) \leq P \leq \max \left\{\Delta I,((1-q) / q) c^{\prime}(\Delta I / P)\right\}$

$$
\begin{gathered}
\left(x_{1}^{\mathrm{Ac}}, w_{1}^{\mathrm{Ac}}, p_{1}^{\mathrm{Ac}}\right)=\left(x_{1}^{*},\left(\frac{x_{1}^{*}}{x_{2}^{\mathrm{Ac}}}\right)^{\beta}\left(\Delta I-p_{2}^{\mathrm{Ac}} P\right), 0\right), \\
\left(x_{2}^{\mathrm{Ac}}, w_{2}^{\mathrm{Ac}}, p_{2}^{\mathrm{Ac}}\right)=\left(\theta I_{2}^{\mathrm{Ac}}, 0, c^{\prime-1}\left(\frac{q}{1-q} P\right)\right),
\end{gathered}
$$

where

$$
I_{2}^{\mathrm{Ac}}=I_{2}+c\left(p_{2}^{\mathrm{Ac}}\right)+\frac{q}{1-q}\left(\Delta I-p_{2}^{\mathrm{Ac}} P\right) .
$$

Disincentive-only (audit-only, Aa) region:

$$
\begin{gathered}
\max \left\{\Delta I,((1-q) / q) c^{\prime}(\Delta I / P)\right\}<P<+\infty \\
\left(x_{1}^{\mathrm{Aa}}, w_{1}^{\mathrm{Aa}}, p_{1}^{\mathrm{Aa}}\right)=\left(x_{1}^{*}, 0,0\right), \\
\left(x_{2}^{\mathrm{Aa}}, w_{2}^{\mathrm{Aa}}, p_{2}^{\mathrm{Aa}}\right)=\left(\theta\left(I_{2}+c\left(p_{2}^{\mathrm{Aa}}\right)\right), 0, \frac{\Delta I}{P}\right) .
\end{gathered}
$$

Here, in Region Ac, $x_{2}^{\mathrm{Ac}}$ is decided by $p_{2}^{\mathrm{Ac}}$, and $w_{1}^{\mathrm{Ac}}$ is decided by $x_{2}^{\mathrm{Ac}}$. Similarly, in Region Aa, $x_{2}^{\mathrm{Aa}}$ is decided by $p_{2}^{\mathrm{Aa}}$.

Note that, if the penalty is finite, the contracts under asymmetric information are significantly different from those under symmetric information. We then discuss the properties of the solution to the asymmetric information problem. Then, we have the following results (see Appendix A for the proof).

Corollary 1 Suppose that the penalty is finite. The optimal contract has the following properties:

$$
\begin{array}{ll}
x_{1}^{*}=x_{1}^{\mathrm{A}}=x_{1}^{\mathrm{GW}}, & 0 \leq w_{1}^{\mathrm{A}} \leq w_{1}^{\mathrm{GW}}, \quad p_{1}^{\mathrm{A}}=0, \\
x_{2}^{*}<x_{2}^{\mathrm{A}} \leq x_{2}^{\mathrm{GW}}, & 0=w_{2}^{\mathrm{A}}=w_{2}^{\mathrm{GW}}, \quad 0 \leq p_{2}^{\mathrm{A}}<1,
\end{array}
$$

for any $\mathrm{A}(\mathrm{A} \in\{\mathrm{Ab}, \mathrm{Ac}, \mathrm{Aa}\})$. In particular, we have

$$
\begin{aligned}
& x_{2}^{*}<x_{2}^{\mathrm{Aa}}<x_{2}^{\mathrm{Ac}}<x_{2}^{\mathrm{Ab}}=x_{2}^{\mathrm{GW}}, \\
& 0=w_{1}^{\mathrm{Aa}}<w_{1}^{\mathrm{Ac}}<w_{1}^{\mathrm{Ab}}=w_{1}^{\mathrm{GW}} .
\end{aligned}
$$

Corollary 1 implies that there are five important properties. The first property of the solution is that $x_{1}^{\mathrm{A}}=x_{1}^{*}$ and $x_{2}^{*}<x_{2}^{\mathrm{A}} \leq x_{2}^{\mathrm{GW}}$ for any $\mathrm{A}$. It is less costly for the owner to distort $x_{2}^{\mathrm{A}}$ away from $x_{2}^{*}$ than to distort $x_{1}^{\mathrm{A}}$ away from $x_{1}^{*}$ in equilibrium.

The second property of the solution is that $x_{2}^{\mathrm{A}}<x_{2}^{\mathrm{GW}}$ and $w_{1}^{\mathrm{A}}<w_{1}^{\mathrm{GW}}$ if $p_{2}^{\mathrm{A}}>0$, and that $x_{2}^{\mathrm{A}}=x_{2}^{\mathrm{GW}}$ and $w_{1}^{\mathrm{A}}=w_{1}^{\mathrm{GW}}$ otherwise. In other words, a decrease in $x_{2}^{\mathrm{A}}$ is equivalent to the associated decrease in $w_{1}^{\mathrm{A}}$.

The third property of the solution is that $\left(\Delta I-p_{2}^{\mathrm{A}} P\right)>w_{1}^{\mathrm{A}} \geq 0$ where $\left(\Delta I-p_{2}^{\mathrm{A}} P\right)$ can be regarded as the information rent for the manager in state $I_{1}$. The owner gives the manager in state $I_{1}$ a portion of the information rent. Importantly, note that the information rent is decreasing with $P$.

The fourth property of the solution is that $p_{2}^{\mathrm{A}}$ is unimodal with $P$. The reason is that $p_{2}^{\mathrm{Ac}}$ is in-creasing and concave with $P$, while $p_{2}^{\mathrm{Aa}}$ is de-creasing and convex with $P$. The first statement is straightforward because $c(p)$ is increasing and convex with $p$. The second statement is shown by $p_{2}^{\mathrm{Aa}}=\Delta I / P$ at the optimum.

The final property of the solution is that an increase in the penalty $P$ moves the contract $M^{\mathrm{A}}$ from the incentive-only $(\mathrm{Ab})$ region to the disincentive-only (Aa) region via the combination (Ac) region. This property is intuitive as follows. For example, the larger the penalty $P$ is, the more available the disincentive mechanism. Then, an increase in the penalty encourages the owner to use the disincentive mechanism rather than the incentive mechanism.

So far we have only considered the finite penalty. Now we examine the case of the unlimited penalty. Although the unlimited penalty is unrealistic, we are interested in considering how the contract changes as the penalty increases.

Recall that, under asymmetric information, there exists a distortion in three $\left(x_{2}^{\mathrm{A}}, w_{1}^{\mathrm{A}}, p_{2}^{\mathrm{A}}\right)$ of the six components of the contract, and that we have

$$
x_{2}^{\mathrm{Aa}}=\theta\left(I_{2}+c\left(p_{2}^{\mathrm{Aa}}\right)\right), \quad w_{1}^{\mathrm{Aa}}=0, \quad p_{2}^{\mathrm{Aa}}=\frac{\Delta I}{P},
$$


for $P>\max \left\{\Delta I,((1-q) / q) c^{\prime}(\Delta I / P)\right\}$. It is straightforward to show that $p_{2}^{\mathrm{Aa}} \rightarrow 0$ as $P \uparrow+\infty$. Thus, these results are summarized as follows.

Corollary 2 The contracts under symmetric information are approximated closely as the penalty is increased without limit. As $P \uparrow+\infty$, we have

$$
x_{2}^{\mathrm{A}} \downarrow x_{2}^{*}, w_{1}^{\mathrm{A}} \downarrow 0, p_{2}^{\mathrm{A}} \rightarrow 0 .
$$

Recall that the solution in the symmetric information problem is the same as in the standard real options model. Thus, in contrast with previous papers under asymmetric information, we show that there is a relationship between the symmetric and asymmetric information problems. From Proposition 1 and Corollary 2, we have the following results.

Remark 1 The solution in the incentive-only $(A b) r e-$ gion is exactly the same as in the $G W$ model. The solution for $P=\Delta I$ in the combination (Ac) region turns out to be that in the $S$ model. As the penalty $P$ becomes sufficiently large, the solution in the disincentive-only region in the asymmetric information model converges to in the symmetric information model developed by MS.

The first statement is obvious in Proposition 1. As for the second statement, $P=\Delta I$ is endogenously decided in the $\mathrm{S}$ model as shown in Appendix B. Thus, we have the second statement from Proposition 1. The third statement is given by Corollary 2. As a result, Remarks $1 \mathrm{im}-$ plies that the solutions in our model include those in the three related papers.

\subsection{Optimal Values}

For all three feasible regions, substituting the solutions into the owner's and manager's option values, $\pi_{\mathrm{o}}^{\mathrm{A}}(x)$ and $\pi_{\mathrm{m}}^{\mathrm{A}}(x)$, respectively, yields

$$
\pi_{\mathrm{o}}^{\mathrm{A}}(x)=q\left(\frac{x}{x_{1}^{*}}\right)^{\beta}\left(x_{1}^{*}-I_{1}\right)+(1-q)\left(\frac{x}{x_{2}^{\mathrm{A}}}\right)^{\beta}\left(x_{2}^{\mathrm{A}}-I_{2}^{\mathrm{A}}\right)
$$

where

$$
I_{2}^{\mathrm{A}}=I_{2}+c\left(p_{2}^{\mathrm{A}}\right)+\frac{q}{1-q}\left(\Delta I-p_{2}^{\mathrm{A}} P\right)
$$

and

$$
\pi_{\mathrm{m}}^{\mathrm{A}}(x)=q\left(\frac{x}{x_{2}^{\mathrm{A}}}\right)^{\beta}\left(\Delta I-p_{2}^{\mathrm{A}} P\right)
$$

Because $\pi^{\mathrm{A}}(x):=\pi_{\mathrm{o}}^{\mathrm{A}}(x)+\pi_{\mathrm{m}}^{\mathrm{A}}(x)$, the total value $\pi^{\mathrm{A}}(x)$ is

$$
\begin{aligned}
\pi^{\mathrm{A}}(x)= & q\left(\frac{x}{x_{1}^{*}}\right)^{\beta}\left(x_{1}^{*}-I_{1}\right) \\
& +(1-q)\left(\frac{x}{x_{2}^{\mathrm{A}}}\right)^{\beta}\left(x_{2}^{\mathrm{A}}-I_{2}-c\left(p_{2}^{\mathrm{A}}\right)\right),
\end{aligned}
$$

for any $A \quad(A \in\{A b, A c, A a\})$. Obviously, inefficiency is caused by the second term in state $I_{2}$.

Let us define $\pi_{\mathrm{o}}^{\mathrm{GW}}(x), \pi_{\mathrm{m}}^{\mathrm{GW}}(x)$, and $\pi^{\mathrm{GW}}(x)$ as the owner's, manager's, and total values in the GW model, as shown in Appendix B. Then, we obtain the following results.

Corollary 3 Suppose that the penalty is finite. Then we have

$$
\begin{gathered}
\pi^{*}(x)=\pi_{\mathrm{o}}^{*}(x)>\pi_{\mathrm{o}}^{\mathrm{A}}(x) \geq \pi_{\mathrm{o}}^{\mathrm{GW}}(x), \\
\pi_{\mathrm{m}}^{\mathrm{GW}}(x) \geq \pi_{\mathrm{m}}^{\mathrm{A}}(x) \geq 0=\pi_{\mathrm{m}}^{*}(x) .
\end{gathered}
$$

In particular, the optimal value has the following properties:

$$
\begin{gathered}
\pi^{*}(x)=\pi_{\mathrm{o}}^{*}(x)>\pi_{\mathrm{o}}^{\mathrm{Aa}}(x) \geq \pi_{\mathrm{o}}^{\mathrm{Ac}}(x) \geq \pi_{\mathrm{o}}^{\mathrm{Ab}}(x)=\pi_{\mathrm{o}}^{\mathrm{GW}}(x), \\
\pi_{\mathrm{m}}^{\mathrm{GW}}(x)=\pi_{\mathrm{m}}^{\mathrm{Ab}}(x) \geq \pi_{\mathrm{m}}^{\mathrm{Ac}}(x) \geq \pi_{\mathrm{m}}^{\mathrm{Aa}}(x) \geq 0=\pi_{\mathrm{m}}^{*}(x) .
\end{gathered}
$$$$
\text { Moreover, we obtain }
$$

$$
\pi^{*}(x)>\pi^{\mathrm{A}}(x), \mathrm{A} \in\{\mathrm{Ab}, \mathrm{Ac}, \mathrm{Aa}\} .
$$

Corollary 3 implies that there are three important properties. The first is that $\pi_{\mathrm{o}}^{\mathrm{A}}(x)$ is monotonically increasing in $P$, while $\pi_{\mathrm{m}}^{\mathrm{A}}(x)$ is monotonically decreasing in $P$. The second is that asymmetric information always leads to a decrease in total value for any finite penalty $P$. The third is that we do not always have $\pi^{\mathrm{A}}(x) \geq \pi^{\mathrm{GW}}(x)$ although we always have

$\pi_{\mathrm{o}}^{\mathrm{A}}(x) \geq \pi_{\mathrm{o}}^{\mathrm{GW}}(x)$. In summary, because the set of the incentive-disincentive contracts is enlarged by that of the incentive-only contracts in the GW model, the owner's (manager's) value is always larger (smaller) than in the GW model. However, the sum of these values is not always larger than in the GW model. Thus, depending on the parameters, we have $\pi^{\mathrm{GW}}(x)>\pi^{\mathrm{A}}(x)$. These imply that the owner's rationality does not correspond to the total rationality. We will discuss this result in the next section by using numerical calculations.

In order to measure the "inefficiency" arising from asymmetric information, we define total social loss $L^{\mathrm{A}}(x)$ as

$$
L^{\mathrm{A}}(x):=\pi^{*}(x)-\pi^{\mathrm{A}}(x) \geq 0 .
$$

Here, $L^{\mathrm{A}}(x)$ is strictly positive for any finite penalty $P$. This definition is exactly the same as in Subsection 4.3 of the GW model. We define the total social loss in the GW model as $L^{\mathrm{GW}}(x):=\pi^{*}(x)-\pi^{\mathrm{GW}}(x)$. Obviously from the definition, the properties of total value $\pi^{\mathrm{A}}(x)$ are equivalent to that of total social loss $L^{\mathrm{A}}(x) .{ }^{8}$

As the same as in the contracts, if the penalty $P$ is sufficiently large, the following results are obtained.

Corollary 4 The values under symmetric information are approximated closely as the penalty is increased

\footnotetext{
${ }^{8} \mathrm{We}$ will discuss $L^{\mathrm{A}}(x)$ rather than $\pi^{\mathrm{A}}(x)$ when we investigate inefficiency in social welfare.
} 
without limit. As $P \uparrow+\infty$, we have

$$
\pi_{\mathrm{o}}^{\mathrm{A}}(x) \uparrow \pi_{\mathrm{o}}^{*}(x), \pi_{\mathrm{m}}^{\mathrm{A}}(x) \downarrow \pi_{\mathrm{m}}^{*}(x), \pi^{\mathrm{A}}(x) \rightarrow \pi^{*}(x),
$$

and

$$
L^{\mathrm{A}}(x) \rightarrow 0 .
$$

The owner's and manager's values are monotonic with the penalty $P$. In particular, the owner's value is increasing monotonically in $P$. However, the total value (i.e., total social loss) is non-monotonic with $P$.

\section{Numerical Implications}

This section analyses several of the more important implications of the model by using the numerical examples. Subsection 4.1 investigates the effects of the exogenous maximum penalty on the solutions and values. Subsection 4.2 examines the distortion in asymmetric information, by using the total social loss. Subsection 4.3 examines the stock price reaction to the information released via the manager's investment decision.

In the numerical examples, we define the auditing cost function $c\left(p_{i}\right)$ as

$$
c\left(p_{i}\right)=\alpha \frac{p_{i}}{1-p_{i}}, \quad i \in\{1,2\}
$$
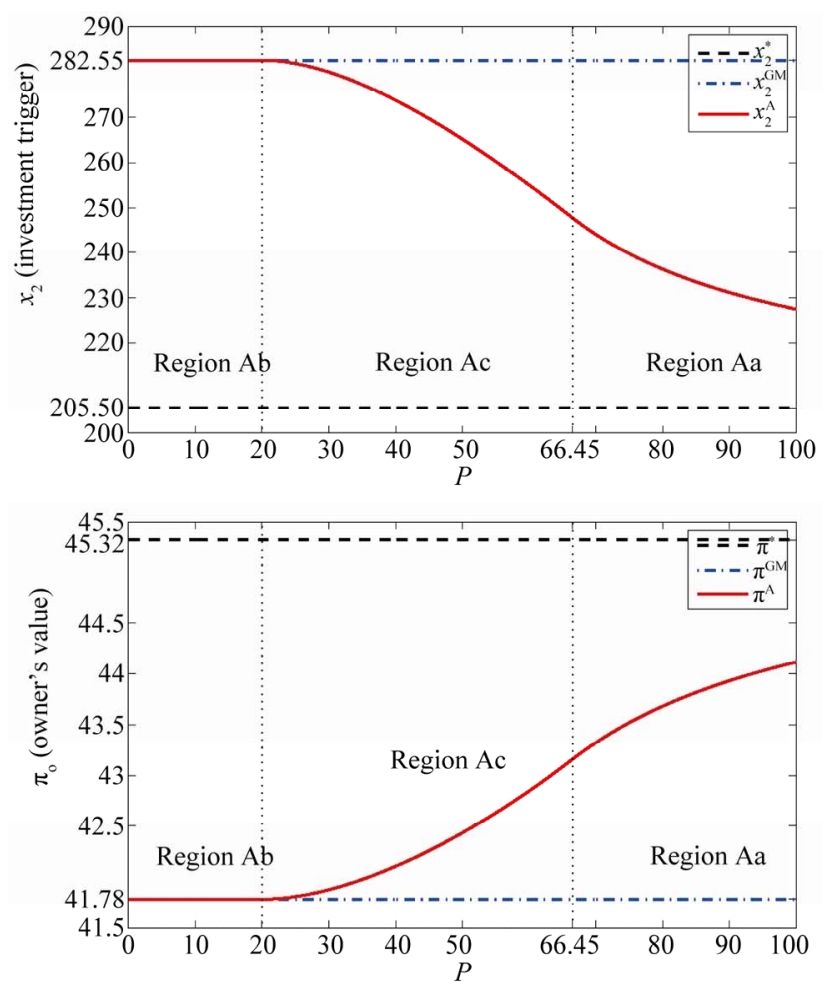

Here, the parameter $\alpha$ is interpreted as a measure of "efficiency" for the auditing cost function. Assume that the basic parameters are $q=0.5, r=0.07, \mu=0.03$, $I_{1}=50, I_{2}=80, \alpha=20, \sigma=0.2$ and $P=40$.

\subsection{Effects of the Penalties}

This subsection considers the effects of the penalties shown in Figure 1.

Under $\alpha=20$, the incentive-only ( $\mathrm{Ab}$ ) region is $0 \leq P<20$, the combination (Ac) region is

$20 \leq P \leq 66.45$, and the disincentive-only (Aa) region is $P>66.45$. First of all, recall that the contracts in the GW model are the incentive-only contracts. The contracts in the incentive-only $(\mathrm{Ab})$ region are the same as those in the GW model because $p_{i}^{\mathrm{A}}=0$ for $i$

$(i \in\{1,2\})$. Next, note that the penalty is equal endogenously to the managers' diverted cash flow, i.e.,

$P=\Delta I=30$. The contract for $P=30$ in the combination region turns out to be the same as that in the $\mathrm{S}$ model. Finally, as $P \uparrow+\infty$, the contracts in the disincentiveonly (Aa) region converge to the symmetric information contracts in the MS model.

The upper left-hand side panel of Figure 1 depicts the investment trigger $x_{2}^{\mathrm{A}}$ with respect to the penalty $P$ $(\mathrm{A} \in\{\mathrm{Aa}, \mathrm{Ab}, \mathrm{Ac}\})$. We see that $x_{2}^{\mathrm{A}}$ is decreasing mo-
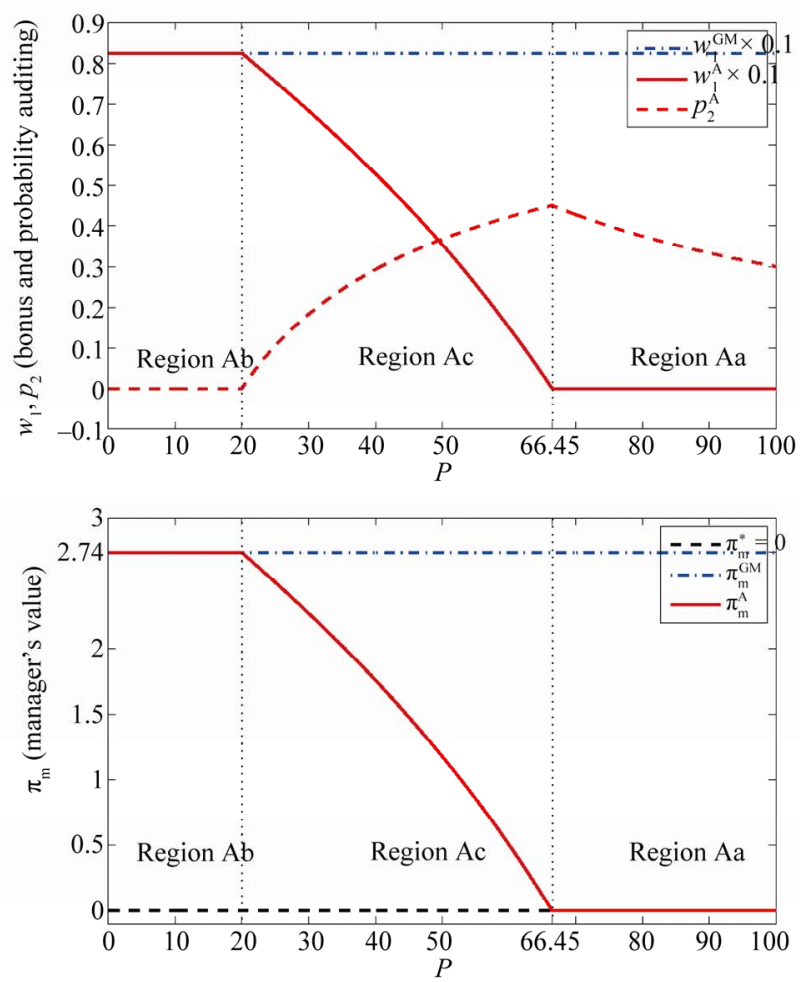

Figure 1. The effects of penalty. This figure illustrates the effects of the penalty on the investment trigger (upper left-hand side panel) the bonus and probability of an audit (upper right-hand side panel), owner's value (lower left-hand side panel), and manager's values (lower right-hand side panel). The incentive-only (bonus-only, Ab) region is $0 \leq P \leq 20$, the combination (Ac) region is $20 \leq P \leq 66.45$, and the disincentive-only (audit-only, Aa) region is $P>66.45$. 
notonically in $P$ with $x_{2}^{\mathrm{GW}} \geq x_{2}^{\mathrm{A}} \geq x_{2}^{*}$.

The upper right-hand side panel demonstrates the bonus incentive and the probability of auditing, $w_{1}^{\mathrm{A}}$ and $p_{2}^{\mathrm{A}}$, with respect to $P$. On the one hand, $w_{1}^{\mathrm{A}}$ is decreasing with $P$ although $w_{1}^{\mathrm{GW}}$ is constant with $P$. On the other hand, $p_{2}^{\mathrm{A}}$ is unimodal with $P$. In particular, as explained earlier, $p_{2}^{\mathrm{Ac}}$ is increasing and concave with $P$, while $p_{2}^{\text {Aa }}$ is decreasing and convex with $P$.

The lower right-hand side panel depicts the owner's option values $\pi^{*}(x)$ and $\pi_{\mathrm{o}}^{\mathrm{A}}(x)$ with respect to $P$. The important result is that $\pi_{\mathrm{o}}^{\mathrm{A}}(x)$ is in between two values, $\pi^{*}(x)$ and $\pi_{\mathrm{o}}^{\mathrm{GW}}(x)$. In addition, $\pi_{\mathrm{o}}^{\mathrm{A}}(x)$ is increasing monotonically with $P$. This property corresponds to the "maximal penalty principle" in the microeconomics literature.

The lower right-hand side panel demonstrates the manager's option values $\pi_{\mathrm{m}}^{*}(x)$ and $\pi_{\mathrm{m}}^{\mathrm{A}}(x)$ with respect to $P$. Recall that the manager's value is zero under symmetric information while it is strictly positive constant under the GW model. The value $\pi_{\mathrm{m}}^{\mathrm{A}}(x)$ is decreasing monotonically with $P$. The reason is that an increase in $P$ decreases the information rent for the manager in state $I_{1}$, which leads to the decrease in the bo-nus-incentive.

The upper right-hand and lower left-hand side panels imply that an increase in $P$ leads to "asset substitution" between the owner and the manager. Wealth is transferred from the manager to the owner by an increase in $P$.

\subsection{Distortion in Asymmetric Information}

This subsection examines the distortion in the social welfare arising from the asymmetric information.

Figure 2 depicts the total social losses $L^{\mathrm{GW}}(x)$ and $L^{\mathrm{A}}(x)$ with respect to $P$. The most interesting result is that $L^{\mathrm{A}}(x)$ is not decreasing monotonically with $P$ although $L^{\mathrm{GW}}(x)$ is constant with $P$. Here, $L^{\mathrm{Ab}}(x)$ is constant with $P$ because it is exactly the same as $L^{\mathrm{GW}}(x)$, while $L^{\mathrm{Aa}}(x)$ is always decreasing with $P$. On the other hand, $L^{\mathrm{Ac}}(x)$ is increasing or decreasing with $P$. Thus, an increase in $P$ does not necessarily lead to a decrease in $L^{\mathrm{A}}(x)$ although it always increases the owner's option value. Consequently, an owner's (individual) rationality does not necessarily lead to total social rationality.

In addition, we consider the comparative statics with respect to $\alpha(\alpha \in\{1,5\})$. Under $\alpha=1$, Region $\mathrm{Ab}$ is $0 \leq P<1$, Region Ac is $1 \leq P \leq 36$, and Region Aa is $P>36$. Under $\alpha=5$, Region $\mathrm{Ab}$ is $0 \leq P<5$, Region Ac is $5 \leq P \leq 45$, and Region Aa is $P>45$. An decrease in the parameter $\alpha$ does not necessarily decrease $L^{\mathrm{A}}(x)$. Consider, for example, $P=25$. Then, $L^{\mathrm{A}}(x)$

\footnotetext{
${ }^{9}$ See Laffont and Martimort [15] for details.
}

under $\alpha=20$ is smaller than under $\alpha=5$. Thus, a reduction in the inefficiency of the auditing cost always benefits the owner, while it does not necessarily increase total social welfare.

\subsection{Stock Price Reaction to Investment}

This subsection investigates the stock price reaction to the manager's investment decision. The stock price is the owner's option value that is given in (15).

Prior to the point at which $x$ reaches the trigger $x_{1}^{*}$, the market does not know the true value of $I$. The market believes that $I=I_{1}$ with probability $q$ and $I=I_{2}$ with probability $1-q$.

Once $x$ hits the trigger $x_{1}^{*}$, the private information is fully revealed. The manager's investment decision signals $I=I_{1}$ to the market. If the manager undertakes the investment at $x_{1}^{*}$, then the stock price instantly jumps upwards to

$$
\pi_{\mathrm{o}}^{\mathrm{A}}\left(x_{1}^{*}\right)=x_{1}^{*}-I_{1}-w_{1}^{\mathrm{A}}, \mathrm{A} \in\{\mathrm{Ab}, \mathrm{Ac}, \mathrm{Aa}\} .
$$

Thus, the jump size in the stock price is $(1-q) J\left(x_{1}^{*}, x_{2}^{\mathrm{A}}, w_{1}^{\mathrm{A}}, p_{2}^{\mathrm{A}}\right)$ where

$$
\begin{aligned}
J\left(x_{1}^{*}, x_{2}^{\mathrm{A}}, w_{1}^{\mathrm{A}}, p_{2}^{\mathrm{A}}\right)= & x_{1}^{*}-I_{1}-w_{1}^{\mathrm{A}} \\
& -\left(\frac{x_{1}^{*}}{x_{2}^{\mathrm{A}}}\right)^{\beta}\left(x_{2}^{\mathrm{A}}-I_{2}-c\left(p_{2}^{\mathrm{A}}\right)\right) .
\end{aligned}
$$

Otherwise, the market assumes $I=I_{2}$. Then the stock price instantly jumps downwards to

$$
\pi_{\mathrm{o}}^{\mathrm{A}}\left(x_{1}^{*}\right)=\left(\frac{x_{1}^{*}}{x_{2}^{\mathrm{A}}}\right)^{\beta}\left(x_{2}^{\mathrm{A}}-I_{2}-c\left(p_{2}^{\mathrm{A}}\right)\right) .
$$

The side of the downwards jump is $q J\left(x_{1}^{*}, x_{2}^{\mathrm{A}}, w_{1}^{\mathrm{A}}, p_{2}^{\mathrm{A}}\right)$. Thus, the sizes of upwards and downwards jumps are the same under $q=0.5$.

The upper left-hand side panel of Figure 3 demonstrates the stock price reaction to investment. Here, we generate stock price paths computed with the same parameters as in the previous section and fixed $P=40$. Then the stock price is 63.42 just prior to $\tau_{1}^{*}=\inf \left\{t \geq 0 ; X_{t} \geq x_{1}^{*}=128.43\right\}$. If the manager undertakes the investment at $\tau_{1}^{*}$, the stock price jumps upwards to 73.13. Otherwise, the stock price jumps downwards to 53.70. Thus, the jump size in the stock price reaction to investment is 9.71 under $P=40 .^{10}$

We begin by investigating the effect of the penalty $P$ on the size of the stock price reaction to investment. Consider a change in the penalty $P$ from 0 to 100 . Our intuitive conjecture is as follows. The jump size in the stock price reaction is decreasing monotonically in $P$

\footnotetext{
${ }^{10}$ In the incentive-only contracts in the GW model, the stock price jumps from 62.93 upwards and downwards to 70.18 and 55.69, respectively. The jump size is 7.24 .
} 


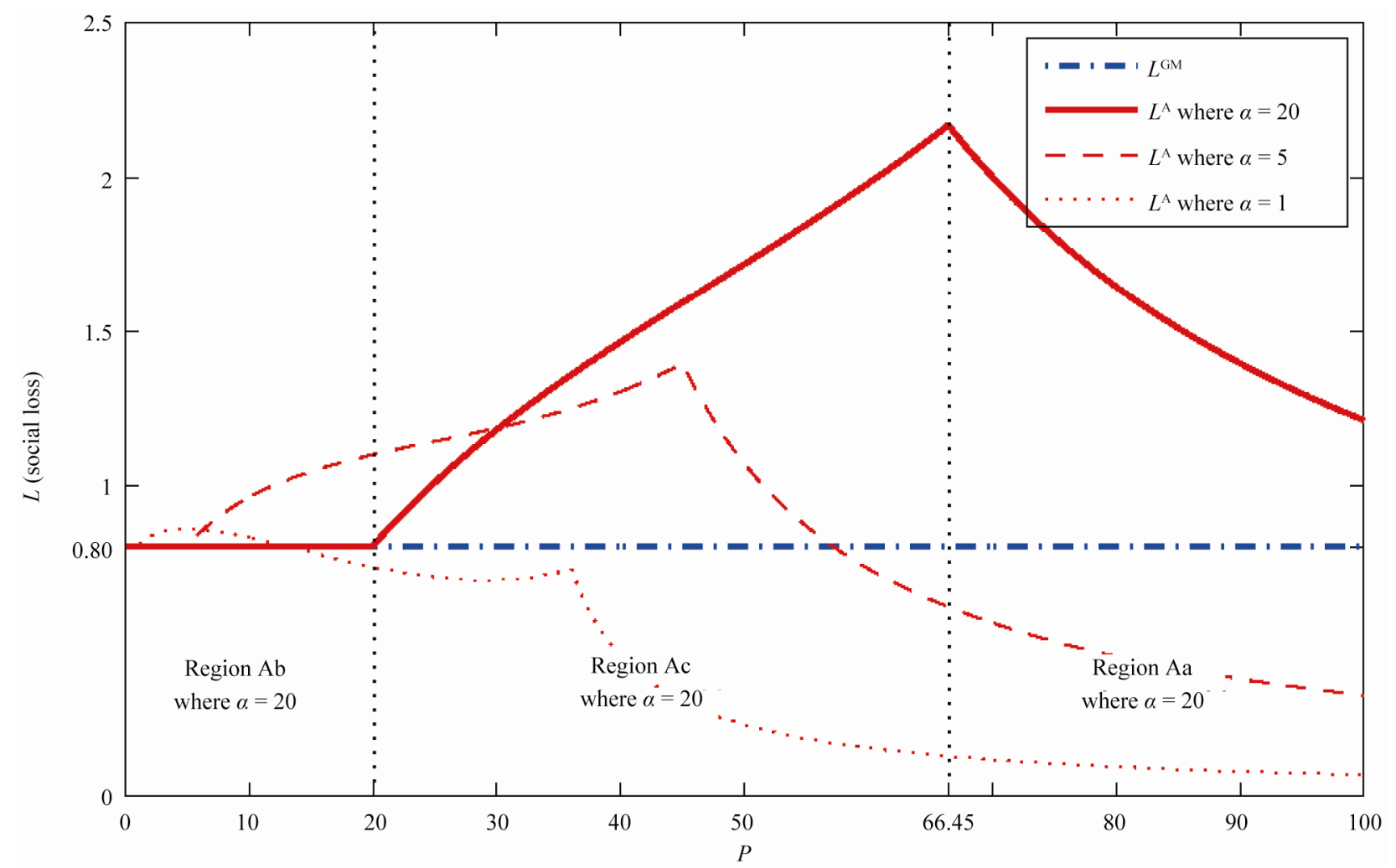

Figure 2. Total social loss with respect to penalty. The total social loss $L^{\mathrm{A}}(x)$ is non-monotonic with $P$. In addition, $L^{\mathrm{A}}(x)$ is not necessarily decreasing with $\alpha$. Under $\alpha=1$, Region Ab is $0 \leq P \leq 1$, Region Ac is $1 \leq P \leq 36$, and Region Aa is $P \geq 36$. Under $\alpha$ $=5$, Region $A b$ is $0 \leq P \leq 5$, Region Ac is $5 \leq P \leq 45$, and Region $A$ a is $P \geq 45$.

because the difference in the stock prices between the symmetric and asymmetric information problems is decreasing monotonically in the exogenous penalty $P$, shown in the left-hand side panel of Figure 1. Interestingly, however, contrary to our intuitive conjecture, the jump size in the stock price reaction need not be monotonic in $P$, shown in the upper right-hand side panel of Figure 3. The reason is that $p_{2}^{\mathrm{A}}$ is non-monotonic with $P$. This result is also new and not shown by the GW model where $p_{2}^{\mathrm{A}}=0$. Note that the jump size in the GW model corresponds to that in the incentive-only region $(0 \leq P \leq 20)$ in our model.

Therefore, in contrast to our intuition, the jump size in the stock price reaction to investment has a $\Lambda$-shaped relation with $P$.

Next, we examine the effect of the volatility parameter $\sigma$, shown in the lower right-hand side panel. The volatility parameter $\sigma$ is changed from 0 to 0.4 . The other parameters are unchanged. We see that the jump size in our model and the GW model are 9.71 and 7.24 under $\sigma=0.2$, respectively. Here interestingly, the jump size in our model is increasing in $\sigma$, while in Grenadier and Wang [2] it is decreasing in $\sigma$. The reason is that the probability is a $\Lambda$-shaped curve with $\sigma$.

Finally, we examine the effect of efficiency measure $\alpha$ on the auditing cost function, shown in the lower right-hand side panel. The efficiency measure $\alpha$ for the auditing cost function is changed from 10 to 40. Again, contrary to our intuition, the jump size in the stock price reaction to investment is decreasing in $\alpha$.

\section{Concluding Remarks}

Our paper extended the investment timing decision problem under asymmetric information by adopting the enlarged set of incentive-disincentive contracts framework. Investment timing under asymmetric information is delayed, compared with that under asymmetric information. However, investment timing under asymmetric information converges to the symmetric information investment timing by making the disincentive (penalty) for the manager's untruthful report sufficiently large. Consequently, by adopting the enlarged set of incentive-disincentive contracts framework, we showed that there is a relationship between the symmetric and asymmetric information problems.

We consider the inefficiency in the social welfare under the enlarged set of incentive-disincentive contracts. Based on the fact that the investment timing and stock price (owners' value) in our model are between those of MS and GW, we conjecture intuitively that social welfare 

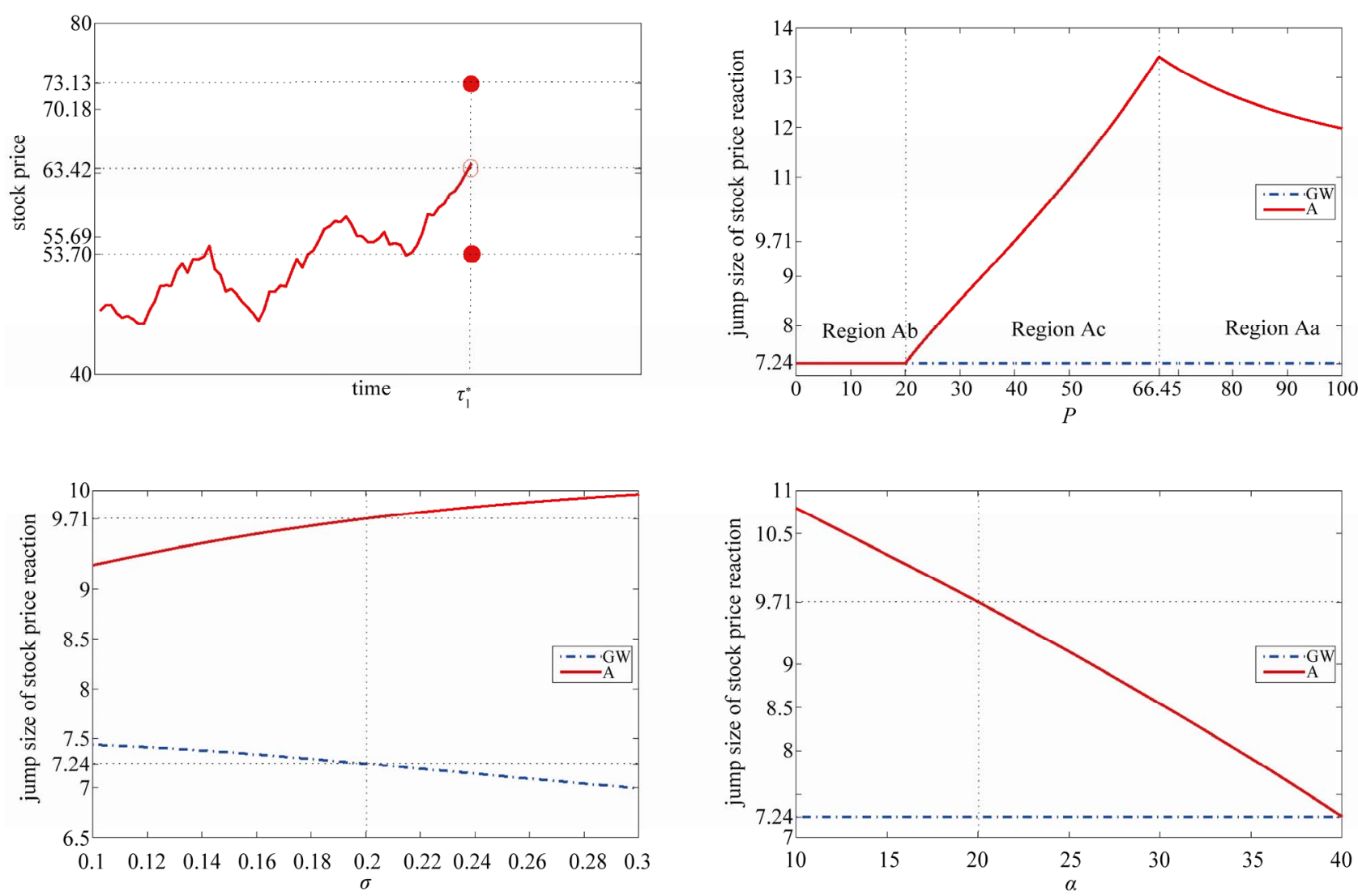

Figure 3. Jump size of stock price reaction to investment. The upper left-hand side panel plots the sample path of the stock price under $P=40$. Once $X_{t}$ arrives at $x_{1}^{*}=128.43$, the private information is fully revealed. The stock price is 63.42 just prior to $\tau_{1}^{*}=\left\{t \geq 0 ; X_{t} \geq x_{1}^{*}\right\}$. If the manager adopts the investment at $\tau_{1}^{*}$, then this action signals $I=I_{1}$ to the market. Thus, the stock price jumps upwards to 73.13. Otherwise, the stock price jumps downwards to 53.70. The jump size is 9.71 under $P$ $=40$. The upper right-hand side panel illustrates the jump size of the stock price reaction to investment for various values of $\boldsymbol{P}$. The jump size has a $\Lambda$-shaped relation with $\boldsymbol{P}$. The lower left-hand side panel depicts the effects of jump size with respect to the volatility. The lower right-hand side panel demonstrate the jump size of the efficiency measure for the auditing cost function.

in our model is also between social welfare in those two papers. However, the result is not necessarily correct. We showed that owners' rationality does not necessarily lead to total social rationality.

\section{REFERENCES}

[1] A. Dixit and R. S. Pindyck, "Investment under Uncertainty," Princeton University Press, Princeton, 1994.

[2] S. R. Grenadier and N. Wang, "Investment Timing, Agency, and Information," Journal of Financial Economics, Vol. 75, No. 3, 2005, pp. 493-533. doi:10.1016/j.jfineco.2004.02.004

[3] H. Weeds, "Strategic Delay in a Real Options Model of R \& D Competition," Review of Economic Studies, Vol. 69, No. 3, 2002, pp. 729-747. doi:10.1111/1467-937X.t01-1-00029

[4] M. Nishihara and M. Fukushima, "Evaluation of Firm's Loss Due to Incomplete Information in Real Investment Decision," European Journal of Operational Research, Vol. 188, No. 2, 2008, pp. 569-585.

\section{doi:10.1016/j.ejor.2007.03.046}

[5] A. E. Bernardo and B. Chowdhry. "Resouces, Real Options, and Corporate Strategy," Journal of Financial Economics, Vol. 63, No. 2, 2002, pp. 211-234. doi:10.1016/S0304-405X(01)00094-0

[6] T. Shibata, "The Impacts of Uncertainties in a Real Options Model under Incomplete Information," European Journal of Operational Research, Vol. 187, No. 3, 2008, pp. 1368-1379. doi:10.1016/j.ejor.2006.09.019

[7] A. Mello and J. J. Parsons, "Measuring the Agency Costs of Debt," Journal of Finance, Vol. 47, No. 5, 1992, pp. 1887-1904. doi: $10.2307 / 2329000$

[8] H. E. Leland, "Agency Costs, Risk Management, and Capital Structure," Journal of Finance, Vol. 53, No. 4, 1998, pp. 1213-1243. doi:10.1111/0022-1082.00051

[9] R. Townsend, "Optimal Contracts and Competitive Markets with Costly State Verification," Journal of Economic Theory, Vol. 33, 1979, pp. 265-293. doi:10.1016/0022-0531(79)90031-0

[10] D. Baron and D. Besanko, "Regulation, Asymmetric Information, and Auditing," RAND Journal of Economics, 
Vol. 15, No. 4, 1984, pp. 447-470. doi: 10.2307/2555518

[11] J. J. Laffont and J. Tirole, "Using Cost Observation to Regulated Firms," Journal of Political Economy, Vol. 94, No. 3, 1986, pp. 614-641. doi:10.1086/261392

[12] T. Shibata, "Investment Timing, Asymmetric Information, and Audit Structure: A Real Options Framework," Journal of Economic Dynamics and Control, Vol. 33, No. 4, 2009, pp. 903-921. doi:10.1016/j.jedc.2008.10.005
[13] R. McDonald and D. R. Siegel, "The Value of Waiting to Invest," Quarterly Journal of Economics, Vol. 101, No. 4, 1986, pp. 707-727. doi:10.2307/1884175

[14] D. Fudenberg and J. J. Tirole, "Game Theory," MIT Press, Cambridge, 1991.

[15] J. J. Laffont and D. Martimort, "The Theory of Incentives: The Principal-Agent Model," Princeton University Press, Princeton, 2002. 


\section{Appendix A. Proof of Lemma and Proposition}

\section{A.1. Proof of Proposition 1}

By omitting $x^{\beta}$, the Lagrangian can be formulated as:

$$
\begin{aligned}
L= & q x_{1}^{-\beta}\left(x_{1}-I_{1}-w_{1}\right)+(1-q) x_{2}^{-\beta}\left(x_{2}-I_{2}-c\left(p_{2}\right)\right) \\
& +\lambda_{1}\left(x_{1}^{-\beta} w_{1}-x_{2}^{-\beta}\left(\Delta I-p_{2} P\right)\right)+\lambda_{2} w_{1}+\lambda_{3} p_{2},
\end{aligned}
$$

where $\lambda_{i} \quad(i \in\{1,2,3\})$ denotes the multiplier on the constraints. The Kuhn-Turker conditions are

$$
\begin{aligned}
\frac{\partial L}{\partial x_{1}}= & q x_{1}^{-\beta}\left(1-\beta x_{1}^{-1}\left(x_{1}-I_{1}-w_{1}\right)\right)-\lambda_{1} x_{1}^{-\beta} w_{1} \beta x_{1}^{-1}=0 \\
\frac{\partial L}{\partial x_{2}}= & (1-q) x_{2}^{-\beta}\left(1-\beta x_{2}^{-1}\left(x_{2}-I_{2}-c\left(p_{2}\right)\right)\right) \\
& +\lambda_{1} x_{2}^{-\beta}\left(\Delta I-p_{2} P\right) \beta x_{2}^{-1}=0 \\
\frac{\partial L}{\partial w_{1}}= & -\left(q-\lambda_{1}\right) x_{1}^{-\beta}+\lambda_{2}=0 \\
\frac{\partial L}{\partial \lambda_{1}}= & x_{1}^{-\beta} w_{1}-x_{2}^{-\beta}\left(\Delta I-p_{2} P\right)=0 \\
\frac{\partial L}{\partial p_{2}}= & -\left((1-q) c^{\prime}\left(p_{2}\right)-\lambda_{1} P\right) x_{2}^{-\beta}+\lambda_{3}=0
\end{aligned}
$$

and

$$
\lambda_{2} w_{1}=\lambda_{3} p_{2}=0, \quad \lambda_{i} \geq 0, \quad i \in\{1,2,3\} .
$$

The solution depends on whether or not $\lambda_{2}$ and $\lambda_{3}$ are equal to zero. First, suppose that $\lambda_{2}>0$ and $\lambda_{3}>0$. Then we have $w_{1}=0$ and $p_{2}=0$ implying $\Delta I=0$, which contradicts $\Delta I>0$. Thus, at least one of $\lambda_{2}$ and $\lambda_{3}$ must be binding. Second, suppose that $\lambda_{2}=0$ and $\lambda_{3}>0$. Then since $\lambda_{1}=q$, we have the solution in the bonus-only $(\mathrm{Ab})$ region with $((1-q) / q) c^{\prime}(0)>P \geq 0$. Third, suppose that $\lambda_{2}=\lambda_{3}=0$. Then we obtain $w_{1}>0$ and $p_{2}>0$. It is straightforward to obtain the solution in the combination (Ac) region. Finally, suppose that $\lambda_{2}>0$ and $\lambda_{3}=0$. Then we have

$P>((1-q) / q) c^{\prime}(\Delta I / P)$, and $P>\Delta I$ because of $p_{2}=\Delta I / P<1$. Thus, we get the solution in the auditonly (Aa) region with $P>\max \left\{((1-q) / q) c^{\prime}(\Delta I / P), \Delta I\right\}$.

\section{A.2. Proof of Corollary 1}

Here, we prove that $x_{2}^{*}<x_{2}^{\mathrm{Aa}}<x_{2}^{\mathrm{Ac}}<x_{2}^{\mathrm{Ab}}$. First, it is easy to obtain $x_{2}^{*}<x_{2}^{\mathrm{Aa}}$ from

$$
x_{2}^{\mathrm{Aa}}=x_{2}^{*}+\theta c\left(p_{2}^{\mathrm{Aa}}\right),
$$

and $c\left(p_{2}^{\mathrm{Aa}}\right)$. Second, $x_{2}^{\mathrm{Aa}}<x_{2}^{\mathrm{Ac}}$ can be proved because of

$$
x_{2}^{\mathrm{Ac}}=x_{2}^{\mathrm{Aa}}+\theta \frac{q}{1-q}\left(\Delta I-p_{2}^{\mathrm{Ac}} P\right),
$$

and $\left(\Delta I-p_{2}^{\mathrm{Ac}} P\right)>0$. Finally, we prove $x_{2}^{\mathrm{Ac}}<x_{2}^{\mathrm{Ab}}$. The trigger $x_{2}^{\mathrm{Ac}}$ is equal to

$$
x_{2}^{\mathrm{Ac}}=x_{2}^{\mathrm{Ab}}+\frac{\beta}{\beta-1}\left(c\left(p_{2}^{\mathrm{Ac}}\right)-c^{\prime}\left(p_{2}^{\mathrm{Ac}}\right) p_{2}^{\mathrm{Ac}}\right) .
$$

Here, we have used $c^{\prime}\left(p_{2}^{\mathrm{Ac}}\right)=(q /(1-q)) P$ at the optimum. Because $c(p)$ is strictly increasing and convex with $p$, the second term is negative. Thus, the proof is complete.

\section{Appendix B. Related Papers}

This appendix explores the two problems in GW and S.

\section{B.1. Grenadier and Wang (GW) Model}

The GW model (asymmetric information problem with the incentive-only mechanism) is formulated as:

$$
\begin{aligned}
& \max _{x_{1}, x_{2}, w_{1}, w_{2}}\left(\frac{x}{x_{1}}\right)^{\beta}\left(x_{1}-I_{1}-w_{1}\right) \\
& +(1-q)\left(\frac{x}{x_{2}}\right)^{\beta}\left(x_{2}-I_{2}-w_{2}\right),
\end{aligned}
$$

subject to

$$
\begin{gathered}
\left(\frac{x}{x_{1}}\right)^{\beta} w_{1} \geq\left(\frac{x}{x_{2}}\right)^{\beta}\left(w_{2}+\Delta I\right), \\
\left(\frac{x}{x_{2}}\right)^{\beta} w_{2} \geq\left(\frac{x}{x_{1}}\right)^{\beta}\left(w_{1}-\Delta I\right), \\
q\left(\frac{x}{x_{1}}\right)^{\beta} w_{1}+(1-q)\left(\frac{x}{x_{2}}\right)^{\beta} w_{2} \geq 0, \\
w_{i} \geq 0, \quad i \in\{1,2\} .
\end{gathered}
$$

At the optimum, we can simplify the problem as follows:

$$
\max _{x_{1}, x_{2}} q\left(\frac{x}{x_{1}}\right)^{\beta}\left(x_{1}-I_{1}\right)+(1-q)\left(\frac{x}{x_{2}}\right)^{\beta}\left(x_{2}-I_{2}-\frac{q}{1-q} \Delta I\right) .
$$

Equation (B.1) means that the owner's value is reduced by the term $(q /(1-q)) \Delta I$, compared with the symmetric information problem defined by (10). The optimal contracts are obtained by

$$
\begin{gathered}
\left(x_{1}^{\mathrm{GW}}, w_{1}^{\mathrm{GW}}\right)=\left(x_{1}^{*},\left(\frac{x_{1}^{*}}{x_{2}^{\mathrm{GW}}}\right)^{\beta} \Delta I\right), \\
\left(x_{2}^{\mathrm{GW}}, w_{2}^{\mathrm{GW}}\right)=\left(\theta\left(I_{2}+\frac{q}{1-q} \Delta I\right), 0\right) .
\end{gathered}
$$

The superscript "GW" refers to the optimum in the GW model. The owner's, manager's, total values are 
given as

$$
\begin{aligned}
\pi_{\mathrm{o}}^{\mathrm{GW}}(x)= & q\left(\frac{x}{x_{1}^{*}}\right)^{\beta}\left(x_{1}^{*}-I_{1}\right) \\
& +(1-q)\left(\frac{x}{x_{2}^{\mathrm{GW}}}\right)^{\beta}\left(x_{2}^{\mathrm{GW}}-I_{2}-\frac{q}{1-q} \Delta I\right), \\
\pi_{\mathrm{m}}^{\mathrm{GW}}(x)= & q\left(\frac{x}{x_{2}^{\mathrm{GW}}}\right)^{\beta} \Delta I, \\
\pi^{\mathrm{GW}}(x)= & q\left(\frac{x}{x_{1}^{*}}\right)^{\beta}\left(x_{1}^{*}-I_{1}\right)+(1-q)\left(\frac{x}{x_{2}^{\mathrm{GW}}}\right)^{\beta}\left(x_{2}^{\mathrm{GW}}-I_{2}\right),
\end{aligned}
$$

where $x<x_{1}^{*}$.

\section{B.2. Shibata (S) Model}

The Shibata model (asymmetric information problem with the incentive-disincentive mechanism with limitedliability constraints on penalties) is defined by:

$$
\begin{array}{r}
\max _{x_{1}, x_{2}, w_{1}, w_{2}, p_{1} \cdot p_{2}, P_{1}, P_{2}} q\left(\frac{x}{x_{1}}\right)^{\beta}\left(x_{1}-I_{1}-w_{1}-c\left(p_{1}\right)\right) \\
+(1-q)\left(\frac{x}{x_{2}}\right)^{\beta}\left(x_{2}-I_{2}-w_{2}-c\left(p_{2}\right)\right),
\end{array}
$$

subject to

$$
\begin{aligned}
& \left(\frac{x}{x_{1}}\right)^{\beta} w_{1} \geq\left(\frac{x}{x_{2}}\right)^{\beta}\left(w_{2}+\Delta I-p_{2} P_{1}\right), \\
& \left(\frac{x}{x_{2}}\right)^{\beta} w_{2} \geq\left(\frac{x}{x_{1}}\right)^{\beta}\left(w_{1}-\Delta I-p_{1} P_{2}\right), \\
& q\left(\frac{x}{x_{1}}\right)^{\beta} w_{1}+(1-q)\left(\frac{x}{x_{2}}\right)^{\beta} w_{2} \geq 0, \\
& w_{i} \geq 0, \quad i \in\{1,2\}, \quad P_{1} \leq w_{2}+\Delta I, \quad P_{2} \geq w_{1}-\Delta I, \\
& 1 \geq p_{i} \geq 0, \quad i \in\{1,2\} .
\end{aligned}
$$

Then, we obtain $w_{2}^{\mathrm{S}}=0, p_{1}^{\mathrm{S}}=0, P_{1}^{\mathrm{S}}=\Delta I$ and $P_{2}^{\mathrm{S}}=\Delta I$ where the superscript "S" refers to the optimum in the $\mathrm{S}$ model, and reduce the number of constraints to only one:

$$
\begin{aligned}
& \max _{x_{1}, x_{2}, p_{2}} q\left(\frac{x}{x_{1}}\right)^{\beta}\left(x_{1}-I_{1}\right)+(1-q) \\
& \times\left(\frac{x}{x_{2}}\right)^{\beta}\left(x_{2}-I_{2}-\frac{q}{1-q} \Delta I\left(1-p_{2}\right)-c\left(p_{2}\right)\right),
\end{aligned}
$$

subject to $p_{2} \geq 0$. Equation (B.2) is reduced by the term $(q /(1-q)) \Delta I\left(1-p_{2}\right)+c\left(p_{2}\right)$, compared with (10) in the symmetric information problem. The optimal contracts are obtained as follows. If $c^{\prime}(0) \leq(q /(1-q)) \Delta I$, $M^{\mathrm{S}}$ turns out to be:

$$
\begin{aligned}
& \left(x_{1}^{\mathrm{S}}, w_{1}^{\mathrm{S}}, p_{1}^{\mathrm{S}}, P_{1}^{\mathrm{S}}\right)=\left(x_{1}^{*},\left(\frac{x_{1}^{*}}{x_{2}^{\mathrm{S}}}\right)^{\beta} \Delta I\left(1-p_{2}^{\mathrm{S}}\right), 0, \Delta I\right), \\
& \left(x_{2}^{\mathrm{S}}, w_{2}^{\mathrm{S}}, p_{2}^{\mathrm{S}}, P_{2}^{\mathrm{S}}\right)= \\
& \left(\theta\left(I_{2}+c\left(p_{2}^{\mathrm{S}}\right)+\frac{q}{1-q} \Delta I\left(1-p_{2}^{\mathrm{S}}\right)\right), 0, c^{\prime-1}\left(\frac{q}{1-q} \Delta I\right), 0\right) .
\end{aligned}
$$

Otherwise, the solutions are equal to those in which $p_{2}^{\mathrm{S}}=0$ is substituted. The owner's, manager's, and total values become

$$
\begin{aligned}
& \pi_{\mathrm{o}}^{\mathrm{S}}(x)=q\left(\frac{x}{x_{1}^{*}}\right)^{\beta}\left(x^{*}-I_{1}\right) \\
& +(1-q)\left(\frac{x}{x_{2}^{\mathrm{s}}}\right)^{\beta}\left(x_{2}^{\mathrm{S}}-I_{2}-\frac{q}{1-q} \Delta I\left(1-p_{2}^{\mathrm{s}}\right)-c\left(p_{2}^{\mathrm{s}}\right)\right), \\
& \pi_{\mathrm{m}}^{\mathrm{s}}(x)=q\left(\frac{x}{x_{2}^{\mathrm{s}}}\right)^{\beta} \frac{q}{1-q} \Delta I\left(1-p_{2}^{\mathrm{s}}\right), \\
& \pi^{\mathrm{S}}(x)=q\left(\frac{x}{x_{1}^{*}}\right)^{\beta}\left(x^{*}-I_{1}\right) \\
& +(1-q)\left(\frac{x}{x_{2}^{\mathrm{s}}}\right)^{\beta}\left(x_{2}^{\mathrm{s}}-I_{2}-c\left(p_{2}^{\mathrm{s}}\right)\right),
\end{aligned}
$$

where $x<x_{1}^{*}$. 